\title{
SAVED BY ROCK 'N' ROLL: LOU REED, HIS FANS AND THE BECOMING OF THE (MARGINAL) SELF
}

Thaddeus Muller

Lou was more than a pop icon; more than a rock and roll star.

$$
\text { - } \mathrm{Jim}^{1} \text { from Philadelphia }
$$

\begin{abstract}
My focus in this article is on the meaning that rock music has for fans of Lou Reed. I use the comments following his death as my primary data. These data were posted on the New York Times website in the comments section following the report "Outsider Whose Dark, Lyrical Vision Helped Shape Rock 'n' Roll." From these data I develop what I call "the marginal self" in reference to how rock music helps self-identified marginalized persons to deal with their social exclusion and alienation. Drawing on Kobarba's (2012) analytic categories of the self, I will show how these data give insight into a wide range of existential meanings related to the music of Lou Reed. For many who wrote these comments their reading of Lou Reed has been an essential transformative part of their life in similar ways to baby boomers as outlined in Kotarba's (2012) Baby Boomers Rock ' $n$ ' Roll Fans: The Music Never Ends. I first show how Kotarba's (2012) core concepts of the musical self provide insight into how fans of Lou Reed develop a sense of self through Reed's music. I then turn to a discussion of the marginalized self as a development of Kotarba's (2012) categories of "authenticity work" and "becoming of the self." Suggestions for future research are noted.
\end{abstract}

Keywords: Lou Reed, Rock 'n' Roll, The Self;

\section{INTRODUCTION}

October 272013 was a cold wet day in the Netherlands. Sunday evening, I was sitting on the couch watching TV, when I heard my wife shout at me while she was running down the stairs: "Lou Reed died." Soon I received text-messages from friends, others called me that evening and the following days. I felt sad he was gone. Many others posted comments in

\footnotetext{
${ }^{1}$ I have changed the names of the commentators in order to protect their privacy.
} 
online forums that expressed similar feelings. These data give insight into a wide range of existential meanings related to the music of Lou Reed. DeNora (1999) states that music can be thought of "as a technology of the self," an essential part of on-going identity work. "Key here is that music's specific properties may contribute to colour the shape and quality of social experience, self-perception and emotion" (DeNora, 1999, p. 53).

DeNora (1999) describes a wide range of uses of music as a technology of the self. For instance, music is a device for memorizing and reliving an important life event and for defining oneself through music. Kotarba (2012), inspired by DeNora, focuses on the social meanings of rock music for a specific demographic: "baby boomers" or people born in the two decades that followed the end of World War II. Kotarba's work informs the research in this article, because many of the authors of the New York Times (NYT) comments identify themselves in their biographical statements as within the baby boomer demographic. For this reason, I draw upon Kotarba's categories to provide insight into the self as it relates to the music of Lou Reed.

According to Kotarba (2012) "becoming of self [that is derived from] the experience of individuality" is the first concept as essential in understanding the social value of rock for baby boomers because this demographic was the first generation whose social life has been shaped by rock music from childhood onward (p. 8). According to Kotarba (1984) the self is:

a unique experience of being within the context of contemporary social condition, an experience most notably marked by an incessant sense of becoming and an active participation in social changes (p. 223).

The self is developed in interactions with others in which meanings of the self are constructed (Blumer, 1969; Goffman, 1959; Mead, 1934). Changes in one's life require a reshaping of the self. The self is an identity project that is never complete. In this process of the becoming of self, one of the major goals is to protect oneself against threats to "the basic security of self." (Douglas, 1984 cited in Kotarba, 2012, p. 9). These threats consist of humiliation, exclusion and alienation. Another goal consists of acquiring rewarding meanings of the self, which results in a sense of self-esteem and empowerment (Kotarba, 1987). For instance, baby boomer's favorite songs from the past provides a sense of security because it helps to create 
continuity and order in their biographies (Kotarba, 2012). At the same time continuing their relation with songs from the past is nurturing and rewarding the self (Kotarba, 2012).

Authenticity is the second concept Kotarba discusses as essential in understanding how baby boomers relate to rock music. Authenticity is an "evaluative concept" (Van Leeuwen, 2003) and therefore a socially constructed phenomenon. Authenticity operates as an essential part of the discourse in the cultural industry, including for our purposes, the music industry, and how the music industry presents artists to the masses (Vannini \& Williams, 2009). Let us consider Lou Reed as an example. In November 1972, Reed was promoted by RCA, a major recording label, as the "original" - a value of authenticity (see Lewin \& Williams, 2009).

...Lou Reed the original - He's been one since the birth of the NY underground and now he is back with a new album. TRANSFORMER, a new album by the original Lou Reed, produced by David Bowie on RCA records and tapes.

The focus herein is on the perspectives of the fans of Lou Reed..Accordign to Kotarba (2012) researchers interested in music should be open to how music helps us to gain a "sense of authenticity or inauthenticity" (emphasis original, p. 12). The experience of inauthenticity can be related to alienation and a lack of deep meaning in one's biography (Kotarba, 2012). Music can render our life meaningful in the sense of feeling (re-)connected with ourselves and others (DeNora 1999). Kotarba uses the concept of "authenticity work," to describe the activity of making claims of (in-) authenticity in musical experiences where mastery of this process “contributes to a valued self” (Kotarba 2012, p. 50).

Drawing primarily upon Kotaraba's (2012) "authenticity work" and "becoming of the self" and also the work of DeNora (1999) I will address the following two questions.

1. Is there any indication in the collected online user-generated comments related to the death of Lou Reed of "authenticity work," and if so, how does it take place?

2. Does the "becoming of self" play an essential part in these online user-generated comments, and if so, in what way? 
In this paper I develop what I call "the marginal self," a theme that allows for the expansion of Kotarba's (2012) analytic categories of "authenticity work" and "becoming of the self." The marginal self refers to how rock music helps marginalized persons to deal with their social exclusion and alienation. I develop this theme in specific relation to fans of the music and character of Lou Reed.

\section{METHOD}

The method used in this study is document analysis or what is known as ethnographic content analyses (ECA) (Altheide \& Schneider 2013). The focus of this method is on the meanings that are constructed within documents understood "as any symbolic representation that can be recorded or retrieved for analysis" (Altheide \& Schneider 2013, p. 7). This method allows researchers to remain in dialogue with documents throughout the research process. The researcher asks questions in relation to the content that they are analyzing and these questions guide the direction of the research. The approach is comparable to qualitative research with an emphasis on constant comparison of documents and theoretical sampling or the focusing on specific relevant segments of the data in order to develop theoretical concepts. During the analysis of the documents one needs to have an open creative approach in order to facilitate the emergence of ideas, patterns, and explanations. This method has an iterative cyclical character, allowing researchers to go back and forth between induction and deduction, and develop new questions and new concepts, which give direction to their research. An essential element of this approach is what I call analytical doubt; researchers should refrain from going for a closure too easily, especially when their 'propositions' tend to be confirmed. The concepts in development have to be checked over and over again in relation to the data in order to acquire analytical depth and refinement until saturation has been reached (Glaser \& Strauss, 1967).

The first step I took was to familiarize myself with the data, which meant (re-)reading all the comments. During this process I started with coding, for which I used (inductive) in vivo concepts, words used by the authors such as "dark" and "New York," and also more abstract theoretical (deductive) concepts like "authenticity work" and "the becoming of self." During this coding process several concepts emerged such as "the marginal self" and "the aging self," as categories related to the becoming of self. I could also link some comments with the variety of self-concepts Kotarba developed in his book, such as the "intimate self" and "the 
timekeeper self." In the end, I had many categories and subcategories, which I used to reorder the comments and sample the ones which were relevant for the two questions noted above.

The documents are in the form of user-generated (i.e., author) "comments," or short reaction statements made in relation to an article published in the New York Times (see Ratilff, 2013). Many comments consist of just one line. For instance, Phil from Westchester county wrote "There will never be another Lou Reed, a true original" whereas John from Sydney wrote: "Dark individual, who promoted heroin use." These types of single line statements provide little insight into the marginalized self that is outlined below.

These two examples highlight the problematic nature of short comments for ethnographic research: a lack of thick description and a lack of contextual information. But even in these short comments we find worthwhile information. The first one is an example of authenticity work; it refers to the concept of a "true original." The second one refers in a negative way to transgression in relation to drugs and this has defined Lou Reed for John from Sydney. Other comments have a narrative format in which much more contextual information is offered. For example Andy from New Jersey provides reference to his own biography:

I look forward to seeing you tonight at the library. Lew Reed performance-poetprovocateur guitarist, lyricist, event maker. In 1966 I saw Lou Reed, Niko, John Cale et alia. in Provincetown performing in Andy Warhol's Exploding Plastic Inevitable, an early work of performance art that rocked the mind as well as the house. There were $16 \mathrm{MM}$ movies projected on the side walls and behind the band, light show, smoke, leather, and weirdly...novelty rubber chickens. Niko was hot, Warhol was cool, Cale was percussive, and Reed was smokin.’ 1942-2013 were interesting years to take a walk on the wild side.

The author relates his own life history to an early performance in Reed's career. This crossing of two biographies is a theme in many comments. There is detailed short description of the concert he visited and his experience of the band and its members. Still, we do not learn a lot about the author except that he was part of the happy few to have seen Warhol's Exploding Plastic Inevitable and was excited by it. However, there is not much information on the becoming of self or authenticity work as described by Kotarba (2012). 
In the spirit of ECA we can raise several questions in relation to these kinds of documents. For instance, what is the age of the author? My best (plausible) guess is that Andy was between 20 and 25 in 1966. So he is probably over 65 if we assume the comment to be true. The last sentence is especially intriguing, what does he mean with taking "a walk on the wild side." Does that relate to him? Perhaps, but I cannot substantiate this from the comment.

During the explorative phase of analysis it became clear that there were many biographical 'thick' narratives in which the "becoming of self" and "authenticity work" play a central role. I decided to focus my attention on these documents of the 600 or so collected.

I started this article with a personal observation for several reasons: first, I want to make clear I am a Lou Reed fan and that I am moved by the content of the documents, although, I sense that I relate in a different way to Reed than most of the authors in the dataset as noted below. Second, while I favor realist ethnography, I also see the value in focusing on one's self as a tool to understand the phenomena we study better.

In this particular case, I have an analytic reason to focus briefly on myself as a Lou Reed fan. On the basis of biographical statements made in the collected data I belong to a different age group than most of the authors. I was born in 1963 and my first experience with Reed was in the early eighties. Probably more importantly, however, I grew up in the Netherlands in a historical period when the societal discourse was in favor of cultural and sexual freedom. Coming from a different generation in a different country and culture, made me realize that in general the authors of the biographical narratives share a perspective which is related to a specific social and cultural context, which I will discuss in this paper. I turn now to a brief sketch of Lou Reed so that unfamiliar readers are able to better relate the data materials.

\section{LOU REED}

It has been speculated that as a young man Lou Reed felt stigmatized and marginalized after his parents sent him to a mental hospital to receive electro shock treatment, because of his subversive behavior and homosexuality, claims disputed by his sister Merrill Reed Weiner (Holpuch, 2015; Weiner, 2015). Weiner (2015) suggests that her brother received shock therapy at the recommendation of a doctor because "he was depressed, weird, anxious, and avoidant." 
As lead singer and songwriter, Reed was one of the founders of the Velvet Underground in the sixties. As a member of the Velvet Underground Reed "helped invent punk rock" a style of music associated with transgression (Macnie, 2001). The Velvet Underground quickly became renowned for their transgressions that included songs about drug use and sexual deviance as well as their use of feedback and distortion as key features of their punk rock stage-act. The band's recordings were a commercial failure upon release and lacked public recognition.

In the early seventies Reed embarked on a solo career. His second album, Transformer (1972), was crucial in his comeback and was produced by influential pop music icon David Bowie, who was a big fan of the Velvet Underground. On Transformer Reed describes the subversive lifestyles in New York City, which culminate in his biggest top 40 hit Walk on the Wild Side. The "era-defining hit" was a commercial success despite its risqué lyrics that touched on drugs and sexuality (Zarrell \& Zakarin, 2013). During this time Reed was rumoured to have had a number of same-sex partners. Better documented, however, is Reed's relationship with a trans woman named Rachel. As noted in a Slate article Reed sometimes referred to Rachel in both genders. In the words of Reed: "Nothing could impress her. He'd hardly heard my music and didn't like it all that much when he did" (Stern, 2013).

In the seventies Reed became a major rock star who played for huge crowds. His live shows became well known because of their intensity and their electrifying character. Drugs use was common during his concerts and Reed himself pretended that he was shooting heroin during the song Heroin (Macnie, 2001). In hindsight, Reed acknowledged that he was actually not true to himself in his most successful years.

It's like I really encouraged it. [...] it's such a drag to have the cult of personality attendant on all this stuff, the whole rock star business is really odious. But I catered to it for a long time [...] you know, as long as they were going that way I thought fuck it, I'll give it a little push that way, a little street theatre (Hibbert, 1989, p. 33).

In the eighties Reed was committed to the belief in "rock ' $n$ ' roll as a serious, redemptive phenomenon" (Reed, 2014, p. 160): 
Rock 'n' roll - you can do so many things with it, but it doesn't seem like so many things are being done with it. But I thought, since I started the Velvet Underground, there's this very big area you can write about seriously, aiming at adults (Reed, 2014, p. 160).

Reed recorded and released 17 albums over the course of his career. Reed was a "massively influential songwriter" who "helped shape nearly fifty years of rock music" (Dolan, 2013). A number of Reed's albums have been critically acclaimed including Transformer (1972) and New York (1989), the latter in which he describes the social and moral decay of New York City in the eighties. Not all of his albums were received positively. Critics were generally unimpressed with the final album Lulu (2011) recorded before his death, a collaboration with the band Metallica. Reed responded in his typical 'indifferent' and uncompromising way: “Who cares?' [...] I'm interested in whether I like it. I write for me.” (Wiederhorn, 2011).

\section{THE BECOMING OF SELF}

Lou Reed's rock music has played an essential part in the lives of his fans. In user-generated comments following Reed's death users refer to life changing moments and periods in which Reed played a crucial role. Many refer to the sixties and the seventies, Jeff from Iowa:

I saw Lou at Memorial Hall in Kansas City in May 2, 1973. I didn't know that night, that over the next four decades, I would count it as the finest concert I'd seen.

Some authors indicate their actual age, but most do not. However, based on the references in the text to certain periods in Lou Reed's career it is possible to estimate the approximate age of each author.The dominant age demographic in the data consists of those that identify themselves to be over 60 years old. This is a demographic defined as baby boomers or those born between 1945 into the late 1960s. Kotarba's (2012) "time keeper self," which refers to memorizing and relating oneself to the past, is a common theme in the comments. A regular way of relating to the past is describing "the first time" experiencing Reed. Ron from NYC:

I still remember discovering the Velvet Underground at Bleeker Bob's in the early 80s as a teenager. The first time I heard "I'm Waiting for the Man," I was hooked. 
Caroline from Brookline:

First heard Take a Walk on the Wild Side while riding with [a] friend on the way to take our SATs [a required test for entry into university]. Couldn't believe my ears.

Marlon from Massachusetts:

I first heard Lou Reed and VU in 1968 after checking out their first album from the public library. (Pretty hip librarians!) "Heroin" for sure changed one impressionable 17 year old in a garage band. Mr. Reed's lyrics always hit the mark because he saw -and described -- the world as it was. Pure emotion. Pure reality. A sad day.

Users also related Lou Reed's music to friends they used to know and the good times they had together. Paul from Illinois describes his social world from the seventies, in which Reed played an important role:

Lou Reed's music could turn any party exotic, while keeping it real. As a military dependent, I remember partying with GIs [soldiers] in a dorm on an air base in Germany in the early 70s right across the street from the security police. Bose 901s cranking out "Heroin" while GIs and long hairs [a reference to hippies] swilled beer and smoked hash together...

Those were the good ol' days of my misspent youth. They wouldn't feel like they do at this distance, poignant and celebratory and quintessentially American, even though no one, probably least of all Lou, would slap an American flag decal on how he brought Americans together in a way no Fourth of July parade ever could.

Stephanie from Los Angeles:

So very grateful to have been a part of the generation that was gifted with the musical artistry of Lou Reed. In 1973/74 I spent many hours listening to Berlin [a 1973 Reed album], with my boyfriend of the time.

As the data reveal, the music of Lou Reed has shaped crucial aspects of the life histories of these fans. In this respect, Reed is as epical or as common as other well-known rock stars. For some fans, some songs have become an essential part of, as Dick Clark once remarked of 
music, the "soundtrack of our lives". Reed's songs become mental markers of the important ritualistic moments of biographies including, weddings, funerals and significant life events. For instance, Reed's album Magic and Loss (1992) the theme of which explored the passing of two of Reed's close friends was referred to in the data as music that was used for funerals. Betty from Maine:

"When you pass through the fire, you pass through humble, you pass through a maze of self-doubt..." [Lou Reed's lyrics from the song "Magic and Loss - The Summation"] I played Magic and Loss at my mother's funeral in 1997. It was perfect and shocking to those in attendance. Thank you, Lou Reed.

Others refer to their favorite wedding song, "Perfect Day"2. Lisa from Canada:

Just this summer, my husband and I picked "Perfect Day" for our first dance at our wedding-- it was perfect. Thanks so much, Lou, and rest in peace!

Some songs are used as indicators of less formalized individual life changing-events, Ray from West Hollywood:

In 1973 I gave "Walk on the Wild Side" to my older brother for his birthday. I guess it was my "coming out" statement to my family. Rip Lou.

\section{THE AGING SELF}

Some of the time keeping has a less celebrative character and is related to grieving, a topic which is not prominent in Baby Boomers Rock ' $n$ ' Roll Fans: The Music Never Ends. For several authors, the death of Lou Reed triggered a specific aspect of the becoming of self for baby boomers, a realization of their "aging self." Reed's death had prompted reflection upon a youthful time with friends. In the following comment of Romeo from New York State we see a reference to the passing of time, combined with the naming of the club where the Velvet Underground played a concert. Romeo reflects upon his experience of the concert.

\footnotetext{
${ }^{2}$ This romantic interpretation is not uncommon, still this is rather ironic because the song has a second layer of meaning referring to the negative self perception of the main character in the song: "you made me forget myself, I thought I was someone else, someone good".
} 
Another leaf falls from my memory tree. /Thank you Lou....I remember Max's and I was fortunate to have been at the Academy of Music for Rock n Roll Animal./ Oh my.

Juliette from NYC is confronted with his own aging:

Thank you, Lou for introducing me to cool. With the news of your passing, I suddenly feel quite old. Peace to you.

Harry from New Jersey also refers to aging and dying in his comment:

The downside of growing old is that the ride comes to an end for all of us at some point. There have been a few heroes I've taken with me on my ride from the 60's to the 10 's, Lou was one of them.

Some authors grieve for those who passed away and reflect on the pain of aging. Jenny from Boston wrote: "one more connection to our collective past gone- the older you get the bigger the hole in your heart." The expression of the pain of the aging self and the longing for a youth long gone plays an important role to Laurie from Brooklyn, NYC:

I grew up with you...with your absolute New York knife-edge music. And with your hard, romantic poetry. [...] I'm 66 now. Where did all that time go? Somedays that time seems like a minute ago...and somedays it's so far away. I miss that world and who I was then. Don't we all miss our youth? I'm grateful to Lou Reed. The deep content of his mind and heart always reached me.

In the next comment, the author refers to a group of friends in the seventies, who bonded though the music of Lou Reed, Mickey from Western Australia:

Having grown up listening to Lou's music in the seventies I suddenly feel very lonely. His influence on me and my mates when we were young is immeasurable...

The aging self has to deal with the loss of youth and the persons one once loved, Jerry from NYC: 
Just listened to Pale Blue Eyes and wept, for Lou, and my youth. Typing through tears. Love to Sam, and Alex, and Lisa, and all those whose memories are inextricable from the music.

In these comments, we can see the aging self differ from the time keeping self, because of the emotions involved such as sadness and pain, but also, because of temporality. The aging self reflects on the present (i.e., experience of the passing of time and the loss of youth) while relating this to the past, while the timekeeping self tends to focus on a transformative moment or a period in the past. A similar historical focus can also be seen in what I have defined as the marginal self, which is an important aspect of the becoming of self, which I will discuss below In the comments the marginal self reflects on its marginal position as an outsider with a spoiled identity and how Reed's music helped to cope with this position. Because authenticity work is crucial in this, I first turn to a discussion of authenticity work.

\section{AUTHENTICY WORK}

One of the main themes in the examined data is authenticity, or the lack of it. It is not only applied to the marginal self, as I will show later, or to the authentic nature of Lou Reed and his music, but authenticity as an evaluative concept is also discussed by users in relation to place and time.

In the data there are several interpretations - 'unique,' 'honest' and 'raw' - which are used to define Lou Reed as authentic. One form of authenticity work is defining Reed as unlike other artists, Delmorefrom Maine: "There was Lou Reed and then there was everyone else." Reed is defined as an uncompromising artist in the sense that he did not give in to commercial pressure to reproduce a hit song for financial gain and popular success. Holly from California described Reed as an "an innovator [...] he was not able to re-create himself...". James from Denver: "His contribution was huge. He was a NY original. [...] and Dean from Tucson, AZ “A true example of American exceptionalism.” Charley from Las Vegas, NV wrote:

Well, at least his long and fruitful life was about uncompromising art. Lou Reed managed to do something many celebrities/artists don't: he stayed completely true to himself. 
Others refer to 'honesty' and 'truth' in their authenticity claims, which relate to how Lou Reed described social life on the edge of New York. Jo from Brooklyn, NY, "Solid and brutally honest, so very New York. Miss you, man” and Sally from Midwest:

He addressed it in an honest way that carried the sting of truth because it was the truth. He didn't say that drugs were good, and he didn't say that they were bad. He simply said that they were--to coin a phrase, he told it like it was.

Frank from Philadelphia refers to the social world Lou Reed described in his songs:

Dirty Boulevard captured the real New York for better or worse [...]

In other authenticity claims words like 'raw' and 'dark' are used to indicate that Lou Reed did not sugarcoat urban life and showed what happened back-stage. Marty fromVermont: "Stripped down, raw, electric rock/poetry. The experience, haunting and dark, defined Lou Reed to me" and Rachel from Metro makes clear that "Because the words were so raw and real. But there was always a melody. And always a (heart) beat. Will miss him." Jane from Delaware wrote, "Lou brought raw honesty and artistry together as only few have."

For most of these authors, their claims do not have to be substantiated and explained. For ethnographic researchers this is of course a shame, because we would like that these fans would relate it to a concrete experience, an interaction with Lou Reed, mediated or live, in which they sensed his authenticity. Authenticity is a socially constituted form of interactional work that is negotiated and affirmed (Gubrium \& Holstein, 2009; Kotarba, 2009). The comments section of the New York Times becomes the space where the interaction takes place and individuals can be influenced by each other's statements.

But as Kotarba (2012) has stated, authenticity work is also related to claims of inauthenticity. In the case of Lou Reed, the pretense (of being cool). Tom from New York City refers to the words 'real' and 'affectation' in his inauthenticity claim:

People want to be considered to be cool. But, Lou's manifestation of cool with little affect may have been a contrivance for his perception contributed to the perception of for his audience? He never seemed real to me -- a sort of deliberate ambiguous affectation. 
This counterclaim is of importance because it shows that authenticity is a social construct, in which the social value of Lou Reed is defined by the author and reflects his relation with Lou Reed. These authenticity claims therefore reveal an essential characteristic of the some of the authors; they recognize something as authentic or inauthentic, only because they can relate it to their own social experiences, values and their definition of the authentic artist. In the case of Lou Reed, the ideal type is that of the bohemian artist, one who lives for his art and does not bother about societal goals such as financial gain and public recognition.

Authenticity work is not only related to the character of Lou Reed, but also to a certain space and time. Harry from New York:

In a city transformed by $\$ 4000$ a month rents, Citi-bikes, and things banned and where cool is now defined by hollow affectation and organic food, isn't it apropos that Lou Reed leaves to seek the wild side elsewhere?

The 'authentic' New York City that is referred to here is a past New York City, which is the 'idealized' place to take a walk on the wild side. In these kinds of claims there is a rejection of modern social phenomena defined as uncool because it represents a gentrified version of New York City, that includes city-bikes, organic food, Applebee's, strollers, nail-salons, bans and high rents. Ed from Houston reacts to the above comment: "I agree. When did cool become antiseptic?"

In authenticity claims the present is contrasted with a past New York that is described with words as dark, gritty, transgressions and wild side, Candy from Virginia:

I enjoyed Lou Reed's songs (both solo and with the Velvet Underground) that told stories about the dark and gritty side of New York, songs which now serve as a historical record of a city that is now a Disneyfied, gentrified, overpriced, Applebeesridden, more densely populated version of Long Island.

In this comment, authenticity work intersects with what I have discussed above in relation to the aging self. There is not only a longing to a past self, but also to persons one once loved, and a longing to a past time and space. The New York City of "take a walk on the wild side" does not exist anymore for many fans, Jimmy Brown from NYC: 
Lou Reed, together with the dark streets and the transgressions of a New York long since gone, have died and faded into memory. RIP, Mr. Reed.

There is a strong relation between authenticity work and how Lou Reed shaped the self of many of the authors. Polly from Chelsea:

Farewell to the troubadour of New York's mean streets, long ago, before they've were paved with nail salons and strollers. You helped me through my life, from high school to middle-aged adolescence. I always counted on you to speak the truth, and you did.

In this authenticity claim there is not only a reference to the New York of the "mean streets," but also to Lou Reed speaking "the truth," which has been an essential quality in helping the author through life. A similar relation between authenticity and the influence of Lou Reed is evident in a comment from Steve from NY:

Thanks for perfect days! Lou - you were a real original and a template for many that followed. Rest in peace.

The experience of authenticity has been crucial for those who felt they were outsiders. I will explain this in detail in the next section by showing how Lou Reed was used by fans as a cultural source to deal with marginalization and stigmatization.

\section{THE MARGINAL SELF}

With the aging self, fans memorized the way they related to Lou Reed and how they reflect on their own aging self. Here I focus on a specific deep transformative meaning attached to Reed in the past of the authors. His music and his public performance opened up new social avenues, which were beyond what was seen as socially acceptable. Reed, as Lorraine states opened "my eyes to a whole new world, one I still adore to this day, one I am never going to forget. Peace be with you Lou, your friend." Another user, Chuck from New York, saw the Velvet Underground in the sixties and described his experience as an epiphany: "Opened up a world of possibility middle class life in Brooklyn hadn't prepared me for" and Sam from Los Angeles described the influence of Reed as follows: "Thanks for opening some doors, Lou Reed. R.I.P.” 
In the comments of those who reflect more in depth on their biographical circumstances, the authors describe themselves as leading an inauthentic life in which they feel disconnected and alienated, Shelley from Wisconsin:

My High School art teacher brought in Transformer on his reel to reel and played it repeatedly. To say it unscrewed this Wisconsin girl's head is an understatement. Mr. Reed, your influence was important to people like me who felt like they were in the middle of nowhere. Thanks and peace to you.

The experience of recognition became a social anchor for several authors as Jack(ie) explains:

To Laurie and all Lou's loved ones, my heartfelt condolences to you. Lou Reed was a kind of lighthouse for me, since sitting as a young teen in my country Podunk farm house bedroom and reading his interviews with Lester Bangs in Creem, since blasting Metal Machine Music while everyone around me was listening to the Allman Brothers.

Some authors were specific in describing the situations in which Reed became a fundamental source of support in their life. Sylvia wrote of Reed's music:

I did my Lou Reed binge while my husband was at work today. I was the only person I knew who loved his work until my daughter took a liking to it. Lou Reed got me through a very dark time, but I had not listened for a while other than the stuff I listened to in the 80 's. For those who think he was no longer good, listen to newer stuff, it is fantastic. When the Killers did Tranquilize with Lou reed my daughter brought it to my attention knowing I would love it.

Lisa wrote that Lou Reed became a support during her grief for her father:

1990 and Magic and Loss coming out just after my dad had died aged 59 and me in meltdown; Lou's meditations on the loss of Doc Pomus turning into a spirit guide that interwove with my therapy.

Others wrote how Lou Reed's music helped them to accept themselves. Carrie from Main refers to the fact that Lou Reed made her accept herself: "Thank you, Lou. Hearing your words made me realize I'm not crazy." Malcolm from California refers to his hard time of accepting himself. 
Lou Reed was essentially the soundtrack to my coming out years back in the seventies and in some strange way I often felt as if I'd owed him my sanity and my life. I am truly at a loss over what more to say upon hearing this news.

In these examples we can see how music as "a technology of the self" (DeNora, 1999) helps to shape one's self-perception. We also see that in these cases Reed's music is fundamental in constructing a meaningful authentic life in which persons accept themselves and experience self-esteem.

At the same time we see that the experience of authenticity goes beyond the self and is also important for the experience of belonging. The authors of these comments felt alone and alienated and could feel part of an 'imaginary' segment of society because of Reed's songs. Jesus from Ohio describe how important it was to feel there were like-minded others.

Lou Reed.... the man who made it ok to know you weren't fighting alone. That others felt as you did... "Sunday Morning" [a Velvet Underground song] made me feel I was not alone... for that I am forever grateful to Mr. Reed.

A similar experience is being described by Rita from Houston, TX who reflects of the experience of not fitting in as teenagers in the seventies.

During the mid-70's, my sister \& I sang "Take a Walk on the Wild Side" as an anthem. Not that we even remotely understood what it was like to be a transvestite at that time, but we understood how it felt to be an outsider. I suppose all teenagers feel the angst of not belonging. If anything, we felt more connected $b / c$ of his song. And for that, I'm very grateful. RIP, Mr. Reed.

The social experiences described in these comments are similar to those who are stigmatized and experience threats to their selves including what "shady parts" regarding social identity others might know about an individual (Goffman, 1963, p. 78). These authorsalso expressed statements that indicated that they felt alone, not at home, troubled, lost and disconnected. They were able to identify with Lou Reed and empower themselves through his music. Reed became a role model in the sense that his songs, music and public performances made them 
accept themselves despite the fact they differed from mainstream society, Lulu from New Mexico:

My life was irrevocably changed for the better when I bought that first Velvet Underground album in 1967. I still have it, banana peel still on, although now I listen to Lou Reed on more modern media. At least once a week, "Venus in Furs" is my wake-up alarm. My very conservative (very conservative) husband doesn't understand my love for his music, but Lou taught me that I could be exactly who I was, with no apology.

Rufus from D.C describes a similar experience, 20 years later, in which the author describes listening to the songs of the Velvet Underground as an epiphany.

It was during the summer of 1987. I was 18, freshly arrived New York for college. At the now defunct St. Mark's records on St. Marks Pl. in East Village, I bought my first Velvet Underground record. I read about them, knew their importance, but not until I heard "Venus in Furs" and "Heroin" on my first VU album, did I truly understand why. It was a transforming experience. I was tuned to their wavelength, and they made me feel it's ok to be an outsider.

In these comments the authors described the ways they related to Lou Reed, referring to him as a lighthouse, teacher, guide, template, mentor, example and motivation. Reed's music and persona helped fans to accept themselves as they were, be true to themselves, and overcome existential alienation. Reed's display of a 'radical' form of individualism seems to be an essential part of the role-model that Reed was for many, Mo from New York:

Dear Mr. Reed. I wasn't a thing like you; never a rocker, never shot smack, never the center of a scene or even in any scene at all. But, from the time I was 10, listening to you tell all the jim-jims in this town where they could stick it, you were my mentor in non-conformity. Somewhere along the way, I lost the black leather tie you signed in a silver sharpie, once my proudest possession. But I never lost the spirit for the fight. Still doing it. Thanks, man

Jerry from Massachusetts refers to how Reed helped him cope with his life, in which 'radical individualism' continues to play an important role: 
No doubt Lou helped me cope with high school and college and has remained a constant part of my life. He set the example for me of a life lived on his own terms.

For these authors, Reed became an example for how to live a transgressive lifestyle enjoying cultural and social freedom, Jack from Colorado :

Lou Reed didn't just tell us to 'Take a Walk on the Wild Side', he invited us to walk with him. It wasn't about the dark and dangerous NYC of that time, it was about the freedom to be whoever you wanted to be and the freedom to accept those who were being whoever they wanted to be.

\section{CONCLUSION}

The thrust of Kotarba's Baby Boomer Rock ' $n$ ' Roll Fans is that rock music is essential in the becoming of self. It is not only just music, but a wide range social meanings which persons attach to it. Baby boomers have been the first generation whose social life has been shaped by rock music from childhood on. Reed's rock music has had a huge impact on the life of many fans. Reed's music helped shape their "social experience, self-perception and emotion" as explored above (DeNora, 1999, p. 53). Memorizing and reflecting on one's past biography has been related to what Kotarba has described as the time keeping self. To this I have added and developed the concept of the aging self, in which grief is experienced in relation the existential experience of passing time, including themes as lost youth and old friends.

It is clear from the data that authenticity work is crucial in defining Lou Reed, his character and his music. We can see how baby boomers construct authenticity in different ways. For some, Reed is experienced as authentic, and for others, he does not seem real. This has a strong relation with the biography of the authors as expressed in their comments online. For those who recognize in Lou Reed a part of their existential quest, Lou Reed is seen as 'real.' For those who cannot relate to him, Lou Reed is 'hollow.' In this sense, authenticity work is an indication of how the authors define themselves, and how they define their individual relation with Lou Reed. 
This article also shows how authenticity work is applied to Lou Reed as an artist, but also, to a certain historical period and place, which are related to Reed's heydays: New York City of the sixties and seventies, which is described as raw, dark and gritty. This is contrasted with the present urbanity of New York, which is perceived by fans as "Disneyfied" and "hollow." What this article contributes to the work of Kotarba (2012) and DeNora (1999) lies in what I have called the marginal self. The data reveal that authors used rock music as a device for the technology of self. But in several circumstances it was evident that authors felt marginalized, stigmatized and suffered because of their 'spoiled' identity. This article shows how music helps users to gain a sense of authenticity when confronted with a situation in which others might deny or loathe one's sense of authentic self. Lou Reed as a role model was of great influence in protecting their selves against threats, such as humiliation and exclusion and crucial in gaining self-esteem and empowerment.

Paradoxically his display of radical individualism - as exemplified in his 1978 song "Street Hassle" that included the repeated lyric "leave me alone" - became a lifestyle statement, which supported many fans who felt marginalized. Analyzing the biographical narratives on what Lou Reed meant for his fans, it is clear that his non-conformity became a big support to those who felt lost in modern society and alienated from its dominant norms and values. This definition of Lou Reed seems to be closely related to a specific generation that grew up in the sixties and seventies. Their voice dominates the comments posted online in response to the New York Times article “Outsider Whose Dark, Lyrical Vision Helped Shape Rock 'n' Roll." This paper more or less reflects their perspective.

How the reading of his fans relates to Lou Reed is beyond the scope of this article, but it is ironic that Lou Reed stated (in hindsight) that during his career in the seventies during his major rock period he was not true to himself. This is the period most authors refer to when make they make authenticity claims. Lou Reed stated that from the early eighties onward he gained more self-control on what he wanted to do as a rock musician. But this can also be seen as his narrative constructing the becoming of self in relation to authenticity.

I already have mentioned that the use of these documents is problematic for ethnographers (like myself) who desire thick descriptions of interactions and rich contextual information. Nevertheless, I have shown that these comments as data were key to understanding the significance that rock music has for its fans. In this article, we have seen how culture and 
music can be a tool in fighting against stigma and the negative effects of a spoiled identity. In further research, we can use similar biographical narratives in relation to other musicians gathered via a diverse range of methods, such as interviewing, auto ethnography and ethnographic content analysis - in order to gain deeper insight in how rock music shapes biographies and selves.

\section{ACKNOWLEDGEMENTS}

I want to thank Joe Kotarba for organizing the Couch Stone Symposium on Music in 2013 and for his stimulating academic support. I also want to thank Chris Schneider for his editing skills, his knowledge of Lou Reed and for sharing his love for baseball with me.

\section{REFERENCES}

Altheide, D. L., \& Schneider, C. J. (2013). Qualitative media analysis (Vol. 38). Sage.

Blumer, H. (1969). Symbolic interactionism. Englewood Cliffs, NJ: Prentice Hall.

DeNora, T. (1999). Music as a technology of the self. Poetics, 27(1), 31-56.

Douglas, J. (1984). The emergence, security, and growth of the self. In J. Kotarba \& A. Fontana (Eds.) The existential self in society (pp. 69-99). Chicago, IL: University of Chicago Press.

Glaser, B.G.,, \& Strauss, A.L. (1967). Discovery of grounded theory: Strategies for qualitative research. Chicago, IL: Aldine de Gruyter.

Goffman, E. (1959). The presentation of self in everyday life. New York, NY: Doubleday Press.

Goffman, E. (1963). Stigma. New York, NY: Simon \& Schuster, Inc. 
Gubrium, J.F. \& Holstein, J.A. (2009). The everyday work and auspices of authenticity. In Vannini, P. \& Williams, J.P. (Eds). Authenticity in culture, self, and society (pp. 121-138). Farnham, Surrey: Ashgate.

Hebdige, D. (1979). Subculture: The meaning of style. New York: Methuem

Holpuch, A. (2015, April 15). Lou Reed's sister: Singer's electroshock therapy wasn't for homosexuality. The Guardian. Retrieved from http://www.theguardian.com/music/2015/apr/15/lou-reed-sister-mental-healthhomosexuality-rumors

Hibbert, T. (1989) Growing up in public. Q magazine, February, 30- 34.

Kotarba, J. A. (1984). A synthesis: The existential self in society. The existential self in society, 222-234.

Kotarba, J.A. (1987). Adolescents and rock'n' roll. Youth and Society, 18, 323-325.

Kotarba, J.K. (2009). Pop music as a resource for assembling an authentic self: A phenomenological-existential perspective. In Vannini, P. \& Williams, J.P. (Eds). Authenticity in culture, self, and society (pp. 153-170). Farnham, Surrey: Ashgate.

Kotarba, J. A. (2012). Baby Boomer Rock'n'Roll Fans: The Music Never Ends. Scarecrow Press.

Lewin, P. \& Williams, J.P. (2009). The ideology and practice of authenticity in punk subculture. In Vannini, P. \& Williams, J.P. (Eds). Authenticity in culture, self, and society (pp. 65-86). Farnham, Surrey: Ashgate.

Mancie, J. (2001). Lou Reed biography. Rolling Stone. Retrieved from http://www.rollingstone.com/music/artists/lou-reed/biography

Mead, G.H. (1934). Mind, self and society. Chicago, IL: University of Chicago Press. 
Ratliff, B. (2013, October 27). 'Outsider Whose Dark, Lyrical Vision Helped Shape Rock 'n' Roll' in New York Times. Retrieved from

http://www.nytimes.com/2013/10/28/arts/music/lou-reed-dies-at-71.html?_r=0

Reed, J. (2014). Waiting for the man: The life and career of Lou Reed. New York, NY:

Omnibus Press.

Stern, M.J. (2013, October 27). Was Lou Reed the first out rock star? Slate. Retrieved from http://www.slate.com/blogs/outward/2013/10/27/lou_reed_bisexual_was_he the first_out_ro ck_star.html

Van Leeuwen, T. (2003). What is authenticity? Discourse Studies, 3, 392-397.

Vannini, P. \& Williams, J.P. (2009). Authenticity in culture, self, and society. Farnham, Surrey: Ashgate.

Weiner, M. R. (2015, April 11). A family in peril: Lou Reed's sister sets the record straight about his childhood. Medium. Retrieved from https://medium.com/cuepoint/a-family-in-perillou-reed-s-sister-sets-the-record-straight-about-his-childhood-20e8399f84a3

Wiederhorn, J. (2011, 9 December), Lou Reed and Metallica Defend 'Lulu' With Venomous Intensity. Loudwire. Retrieved from www.loudwire.com/lou-reed-metallica-defend-luluvenomous-intensity

Zarrell, R. \& Zakarin, J. (2013, October 27). Music legend Lou Reed dies at 71. Buzzfeed. Retrieved from http://www.buzzfeed.com/rachelzarrell/music-legend-lou-reed-dies-at71\#.yfWYxk3jY 